\title{
Kapitellum ve humerus alt ucunun koronal plan kırıkları
}

\author{
Capitellum and coronal plane fractures of distal humerus
}

\author{
Kerem Bilsel, Fatih Yıldız
}

Bezmialem Vakıf Üniversitesi, Ortopedi ve Travmatoloji Anabilim Dalı, İstanbul

\begin{abstract}
Humerus alt ucunun koronal plandaki kısmi eklem içi kırıkları tüm dirsek kırıklarının \%1'ini ve distal humerus kırıklarının \%6'sını oluşturmaktadır. Bu yaralanmalar yalnızca kapitellumun kırılması şeklinde olabileceği gibi daha mediyale uzanarak troklea veya mediyal epikondili içerebilir, hatta bağ yaralanması ve dirsek çıkığı ile birlikte de görülebilir. Tedavi önceleri kapalı redüksiyon, immobilizasyon ve kırık parçaların eksizyonu şeklinde yapılırken, günümüzde erken eklem hareketlerine izin verecek şekilde kırığın açık, anatomik redüksiyonu, eklem yüzeyinin restorasyonu ve başsız kompresyon vidası, kanselöz kısmi yivli kanüle vida veya Herbert vidası ile stabil tespit prensiplerine göre yapılmaktadır. Ameliyat öncesi planlama yapılarak, yaralanmanın karmaşıklığı ve kırığın şekline göre redüksiyon ve tespit için genişletilmiş lateral yaklaşım, posterior yaklaşım ve olekranon osteotomisi veya anterolateral yaklaşımlardan biri tercih edilebilir. Gerekli donanım ve tecrübe var ise artroskopi yardımlı tespit de uygulanabilir. Açık yerleştirme ve içsel tespit yöntemi ile tedavi edilen kapitellum kırıklı hasta serilerinin sonuçlarını bildiren klinik çalışmalarda fonksiyonel sonuçların hastaların çoğunda iyi ve mükemmel olduğu, ancak nadir de olsa osteonekroz, heterotopik ossifikasyon veya posttravmatik artroz gibi komplikasyonlar ile karşılaşılabileceği belirtilmiştir.
\end{abstract}

Anahtar sözcükler: kapitellum; troklea; koronal plan; kemik kırıkları; kırık sabitlenmesi, internal
Partial articular fractures in the coronal plane of the distal humerus account for $1 \%$ of all elbow fractures and $6 \%$ of distal humeral fractures. This injury may involve only capitellum or extend to more medial part of the distal humerus as trochlea or medial epicondyle, and can be seen even with ligament injury or elbow dislocation. Treatments have evolved from closed reduction, immobilization, and fragment excision to an option for open reduction and internal fixation with headless cannulated screws, cancellous partially threaded screws and Herbert screws to stabilize the articular anatomy that facilitates early mobilization. According to complexity of the injury, type of the fracture and preoperative planning, one of extensile lateral, posterior (with or without olecranon osteotomy) or anterolateral approaches can be preferred for reduction and fixation of the fracture. If adequate instrumentation and experience are available, arthroscopy assisted fixation can be performed. Clinical studies reporting the outcomes of the patient series following open reduction and internal fixation of the capitellar fractures have demonstrated good and excellent functional results in most of the patients but complications like osteonecrosis, heterotopic ossification or posttraumatic arthritis may be rarely seen.

Key words: capitellum; trochlea; coronal plane; bone fractures; fracture fixation, internal

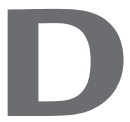
istal humerusun lateral kolonunun koronal plandaki kısmi eklem içi kırıkları, tüm dirsek kırıklarının \%1'ini, distal humerus kırıklarının \%6'sını oluşturmaktadır ve hastaların çoğu genç bayanlardır. ${ }^{[1]}$. Göreceli olarak nadir görülen bu kırıklar doğru olarak tedavi edilmediklerinde dirsek eklem hareket açıklıklarında ciddi kısıtlılığa neden olabildiklerinden, güncel tanı ve tedavi yaklaşımlarını hatırlamakta yarar vardır.
Dirsekte koronal planda makaslama kuvvetlerinin oluşturduğu kırıklar genellikle düşük enerjili bir travma ile açık el üzerine düşme sırasında kuvvetin direkt olarak radius başından veya trokleanın lateral yarısından kapitelluma ulaşması ya da posterolateral dirsek çıkığının spontan redüksiyonu sırasında ${ }^{[2]}$ meydana gelir ve kapitellum, troklea veya her ikisini birden içerebilir. ${ }^{[3,4]}$ Bu kırıklara bağ yaralanması (mediyal kollateral bağ veya lateral ligamentöz kompleks yırtıkları) ve radius

- İletişim adresi: Doç. Dr. Kerem Bilsel, Bezmialem Vakıf Üniversitesi, Ortopedi ve Travmatoloji Anabilim Dalı, Fatih, İstanbul Tel: 0212 - 4531700 e-posta: kbilsel@gmail.com

- Geliș tarihi: 10 Ocak 2014 Kabul tarihi: 10 Ocak2014 
başı kırıkları eşlik edebileceği gibi, kompleks distal humerus kırıklarının ya da dirsek kırıklı çıkıklarının bir parçası olarak da görülebilirler. ${ }^{[3,5]}$

Dirsek ve ön kolun aksiyel stabilitesi için sağlam bir radyokapitellar ekleme intiyaç vardır. Radyokapitellar eklem üzerindeki dinamik kompresyon ile birlikte posterolateral ligamentöz kompleksteki gerginlik, dirsek lateralinin stabilitesinin devamlılığını sağlar. Morrey ve arkadaşları, mediyal kollateral bağ hasarlı dirseklerde valgus strese karşı radius başının önemli bir ikincil stabilizan olduğunu göstermiştir. ${ }^{[6]}$ Benzer şekilde, Dushuttle da mediyal yapıların bütünlüğünün bozulduğu durumlarda kapitellum eksizyonunun dirsekte koronal plan instabilitesine neden olduğunu bulmuştur. ${ }^{[7]}$

\section{FiZiK MUAYENE}

Dirsek yaralanması şikayeti ile acile başvuran her hastada öncelikle vasküler ve nörolojik muayeneler yapılmalı, kompartman sendromu açısından ön kol kompartmanları ve açık kırık açısından yumuşak doku örtüsü dikkatlice değerlendirilmelidir. Kapitellum kırıkları izole olabileceği gibi bağ yaralanmaları veya dirsek çıkıkları ile birlikte de görülebileceğinden, bu hastalar dirsek stabilitesi açısından acil serviste ve eğer ağrı nedeniyle yapılamaz ise ameliyat öncesinde anestezi altında muayene edilmelidir. Kapitellum, kırık sonrası anteriora deplase olma eğilimindedir ve bu nedenle dirsek fleksiyonuna mekanik bir engel oluşturabilir. Bu kırıklar daha çok radius üzerinden aktarılan kompresyon kuvveti nedeni ile meydana geldiğinden muhtemel bir Essex-Lopresti yaralanmasını gözden kaçırmamak için interosseöz membran ve distal radyoulnar eklem muayenesi de yapılmalıdır.

\section{RADYOLOJiK DEĞERLENDIRME}

Bu yaralanmalarda dirsek, ön kol ve el bileği röntgenleri rutin olarak istenmelidir. Dirsek travma serisi olarak ön-arka, lateral ve radyokapitellar görüntüler alınmalıdır. Kapitellum izole olarak kırılabileceği gibi, kompleks dirsek yaralanmasının bir parçası da olabileceğinden sagittal ve koronal plan rekonstrüksiyonlu bilgisayarlı tomografi (BT) ile değerlendirmek tanı ve tedavinin planlanmasında hata yapma riskini azaltacaktır (Şekil 1). Kırığın mediyale uzanımını, eklem yüzündeki çökmeyi, metafizyel ve kondiler parçalanmayı değerlendirmede oldukça yararlı olan BT ile cerrahi yaklaşım ve implant seçimi konusunda karar vermek kolaylaşmaktadır. Üç boyutlu BT görüntülerinin kullanılmasının distal humerus kırıklarının tanımlanması ve sınıflandırılmasında gözlemcilerin kendi içerisinde ve gözlemciler arası güvenilirliği arttırdığı bilinmektedir. ${ }^{[8]}$

Kapitellum koronal plan kırı̆ıı olan hastaların yaklaşık $\% 50$ 'sine ${ }^{[3]}$ beraberinde radius başı, ${ }^{[1,3,5]}$ olekranon, ${ }^{[9]}$ lateral kondi[ ${ }^{[9]}$ ve mediyal epikondi ${ }^{[5]}$ kırı̆̆l, posterolatera[ ${ }^{[1]}$ veya posteromediyal[ ${ }^{[5]}$ ulnohumeral çıkık gibi farklı dirsek çevresi yaralanmalarının da eşlik edebileceği belirtilmiştir. Dubberley'in 28 hastasının üçünde, ${ }^{[3]}$ Ring'in 21 hastasının üçünde, ${ }^{[5]}$ Goodman'ın 8 hastasının ikisinde ${ }^{[9]}$ ve Ruchelsman'ın 16 hastasının beşinde ${ }^{[1]}$ aynı taraf radius başı kırı̆̆ı tespit edilmiştir. Beraberinde lateral ulnar kollateral bağ (LUKB) yaralanması (kısmi ya da tam yırtık) veya fonksiyonel eşdeğeri (lateral epikondil kırığı) olan hastalarda, dirsek stabilitesine katkısı göz önünde bulundurularak LUKB tamiri de yapılmalıdır. LUKB yaralanması değişik serilerde farklı oranlarda (\%6-52) bildirilmiştir ve fonksiyonel yaralanmanın bağ yırtığından daha fazla görüldüğü belirtilmiştir. ${ }^{[1,3,5,10]}$
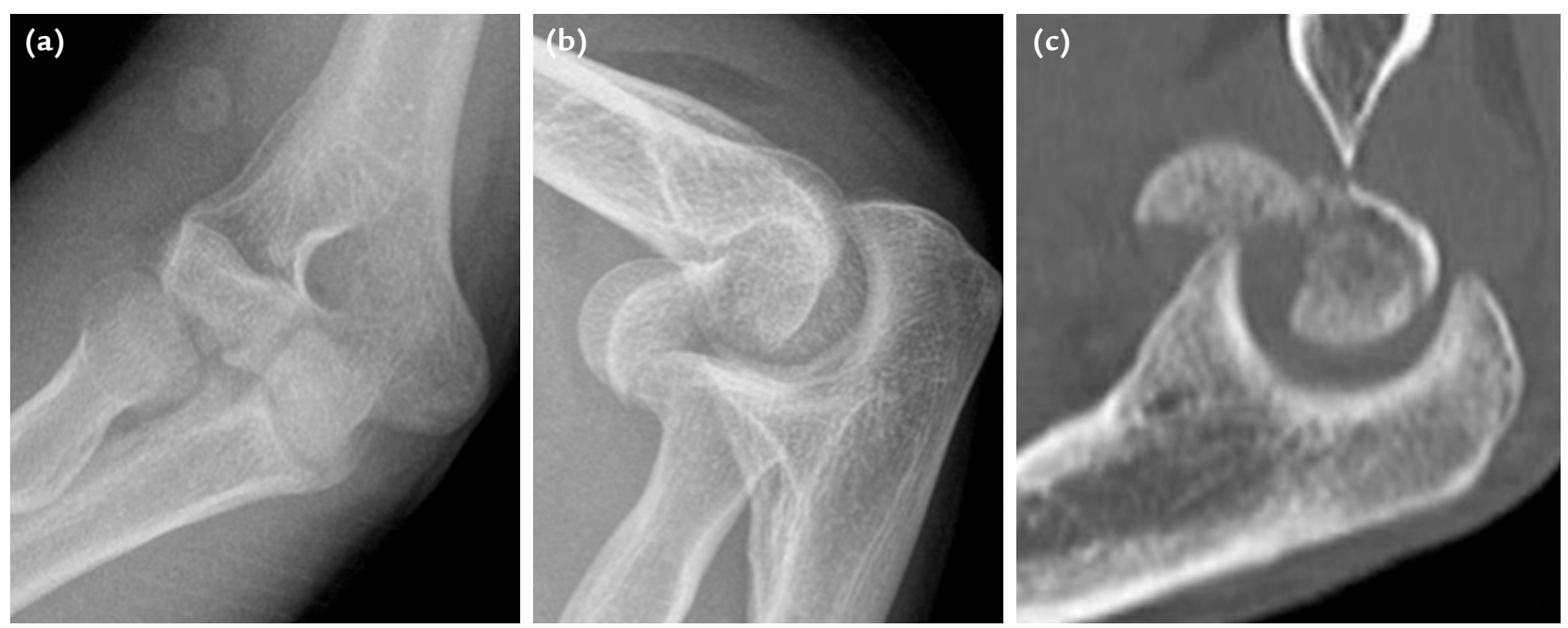

Şekil 1. a-c. Yirmi dört yaşında erkek bir hastada açık el üzerine düşme sonrası ortaya çıkan, kapitellum ve trokleanın bir parçasını da içeren Tip 4 koronal plan kırı̆̆ı. Ameliyat öncesi ön-arka grafi (a), yan grafi (b) ve sagittal BT kesiti (c). 


\section{SINIFLAMA}

Günümüze kadar değişik şekillerde sınıflandırılmış olsalar da, kapitellum kırıklarının henüz herkes tarafından kabul gören tek bir sınıflama sistemi yoktur. ${ }^{[3-5,11,12]}$ AO/OTA (Association for Osteosynthesis / Orthopedic Trauma Association) sınıflama sisteminde kapitellum kırıkları 13-B3 olarak ve izole kapitellum kırıkları B3.1, troklea kırıkları B3.2, kapitellum ve trokleanın sagittal planda ikinci bir kırık hattı ile birlikte olduğu kırıklar B3.3 ve daha kompleks distal humerus kırıklarının bir parçası olduğu durumlar 13-C3.3 olarak sınıflandırılmıştır. Günümüzde en sık kullanılan sınıflama sistemi, Bryan ve Morrey tarafindan tarif edilen (Tip 1-3) ve daha sonra McKee'nin dördüncü tipi eklemesiyle oluşan sistemdir (Şekil 2): Tip 1 yaralanmalarda makaslama kuvvetleri sonucu kapitellumda oluşan büyük bir osseöz kırık fragman vardır ve bu, trokleaya ya hiç uzanmaz ya da çok az bir kısmını içerir (HahnSteinthal kırığı); Tip 2'de makaslama yaralanması sonucu kapitellumda oluşan artiküler kıkırdak kırık fragmanı küçüktür ve çok az miktarda subkondral kemiğe sahiptir (Kocher-Lorenz kırı̆̆ı); Tip 3, kapitellumun parçalı kırığıdır (Broberg-Morrey varyantı). ${ }^{[11]}$ Tip 4'te ise kapitellum ve trokleanın bir kısmı tek bir büyük parça olarak koronal planda kırılmıştır. ${ }^{[4]}$ Ring ve arkadaşları radyolojik ve intraoperatif bulguları temel alan beş farklı yaralanma tipi tanımlayarak (Tip 1, izole kapitellum kırığı; Tip 2, lateral epikondile uzanan kırık; Tip 3 , postero-inferior lateral kolonun metafizinde kırık ile birlikte; Tip 4, posterior trokleada çökme; Tip 5, mediyal epikondile uzanan kırıklar) kırığın redüksiyonu ve eklem yüzünün restorasyonu için ilk dört tipte lateral yaklaşımın, beşinci tipte ise olekranon osteotomisinin gerekeceğini belirtmişlerdir. ${ }^{\left[{ }^{[3}\right.}$ Dubberley ve arkadaşlarının yakın zamanda literatüre kattığı sınıflandırma sistemi de bu kırıkları üç tipe ayırmaktadır: ${ }^{[3]}$ Tip 1 , trokleanın lateral kenarını içeren ya da içermeyen kapitellum kırığı; Tip 2, kapitellum ve trokleanın tek bir parça olarak kırılması; Tip 3 ise kapitellum ve trokleanın farklı parçalar olarak kırılması olarak sınıflandııımıştır. Ayrıca her bir tip, posterior kondilde kırık olup (Tip A) olmamasına (Tip B) göre alt tiplere ayrılmıştır. Dubberley, bu sınıflamanın tedavi ve prognozu belirlemede daha etkin olduğunu belirtmiştir.

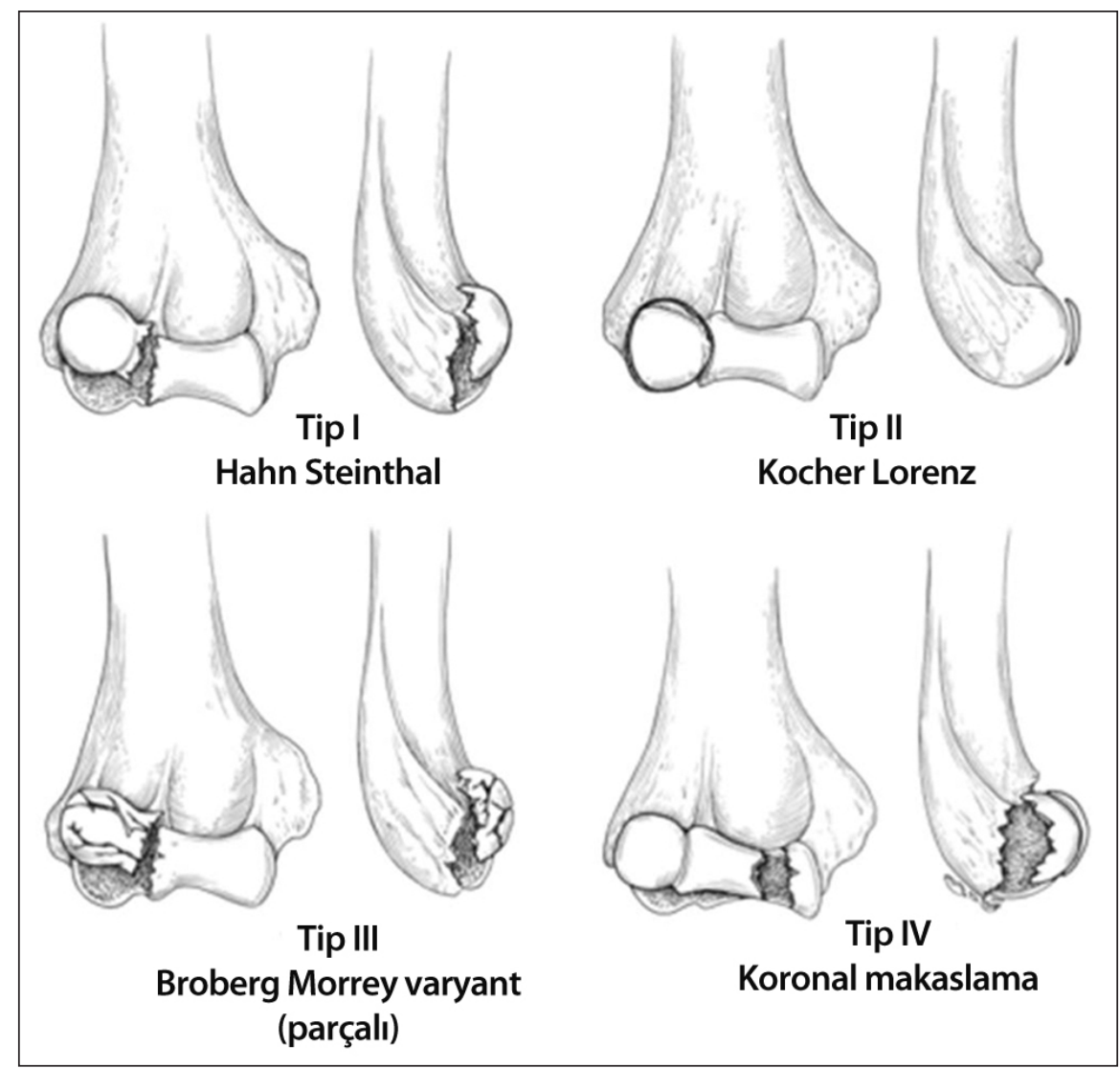

Şekil 2. Bryan ve Morrey'in tanımladığı Tip 1-3'e McKee'nin Tip 4'ü eklemesi ile modifiye olmuş ve günümüzde en sık kullanılan sınıflama. 


\section{TEDAVi}

Kapitellum koronal plan kırıklarının tedavisi önceleri kapalı redüksiyon ve immobilizasyon ${ }^{[7,13]}$ veya fragman eksizyonu ${ }^{[14]}$ şeklinde yapılırken, günümüzde anatomik eklem restorasyonu, stabil osteosentez ve erken hareket prensiplerine göre yapılmaktadır. ${ }^{[4,11,15]}$ Anatomik redüksiyon ve stabil osteosentezin elde edilemediği durumlarda, dirsekte posttravmatik artroz, sertlik, ağrı veya instabilite gibi sorunlarla karşılaşılabilir.

Kapitellum rezeksiyonu ile tedavi edilen hastaların sonuçlarının kötü olması[16], uzun dönemde dirsekte valgus instabilitesi ve ağrılı distal radyoulnar eklem subluksasyonu ${ }^{[17]}$ gibi sorunlarla karşılaşılması nedeniyle bu tedavi yöntemi günümüzde yerini stabil osteosenteze bırakmıştır.

\section{CERRAHI YAKLAŞIMLAR}

Cerrahi tedavi planlanırken muayene bulguları ve BT görüntüleri değerlendirilerek yaralanmanın boyutları ortaya konmalı, kırığın tespiti için hangi insizyonun ve implantların daha uygun olacağı önceden belirlenmelidir. Kırığın redüksiyonu ve tespiti, yaralanmanın karmaşıklık derecesine göre genişletilmiş Kocher insizyonu, posterior kesi ile olekranon osteotomisi veya anterolateral yaklaşım ile yapılabileceği gibi, artroskopi yardımıyla minimal invaziv olarak da yapılabilir. Ring ve arkadaşlarının sınıflandırmasına göre Tip I-IV kırıklarda genişletilmiş lateral yaklaşımın yeterli olacağı, mediyal epikondile uzanım gösteren Tip V kırıklarda ise olekranon osteotomisinin daha iyi bir yaklaşım sağlayacağı belirtilmiştir. ${ }^{[5]}$

\section{Lateral yaklaşım}

Lateral yaklaşım, kapitellum koronal plan kırıklarının tespitinde en sık tercih edilendir. Bu kesi, genellikle hem trokleanın mediyaline uzanım gösteren kapitellum kırıklarının redüksiyonu ve tespiti için hem de radius başı veya LUKB kompleksi yaralanması eşlik eden olguların tedavisi için yeterli bir cerrahi yaklaşım sağlar. ${ }^{[15,18]}$ Hasta kol masasında, supin pozisyonda ve turnike altında hazırlanır. Lateral epikondili ortalayacak şekilde distal humerusun lateralinden radius başının yaklaşık $2 \mathrm{~cm}$ distaline uzanan bir cilt kesisi yapılır. Cilt altı geçildikten sonra lateral epikondil üzerindeki ortak ekstansör kasların insersiyosu beraberindeki anterior kapsül ile birlikte anteriora doğru flep şeklinde kaldırılmalı, insizyon distalinde Kocher intervali bulunarak proksimal kesi ile birleştirilmelidir. Bu esnada posterior interosseöz sinirden (PIN) uzaklaşmak için ön kol pronasyonda tutulmalıdır. Dirsek fleksiyonda iken anterior kapsülün altından mediyal epikondile bir elevatör yerleştirilerek kırık hatları ve eklem yüzeyi ortaya konmuş olur (Şekil 3 ). Kırığın uzanımına göre yaklaşım posteriora doğru da genişletilebilir; ancak LUKB ve kapitellumun kanlanmasını sağlayan yumuşak dokuların korunmasına özen gösterilmelidir.

\section{Posterior yaklaşım ve olekranon ostetomisi}

Lateral insizyon yolu ile troklea veya kırığın mediyal uzanımına yeterince ulaşılamadığı olgularda mediyal yaklaşım ya da posterior insizyon ve olekranon osteotomisine ihtiyaç duyulabilir. Bazı yazarlar, tüm kapitellum koronal plan kırıklarının posterior yaklaşım yolu ile redüksiyonunun ve tespitinin yapılabileceğini, böylece eğer lateral insizyon yetersiz kalır ise çift insizyon yapmış olmanın baştan önüne geçileceğini belirtmişlerdir. ${ }^{[3]}$ Ameliyat öncesi planlama ile trokleada parçalanması ya da mediyal epikondil uzanımı olan kırıklar için posterior yaklaşım ile ameliyata başlanabilir. ${ }^{[5,9]}$
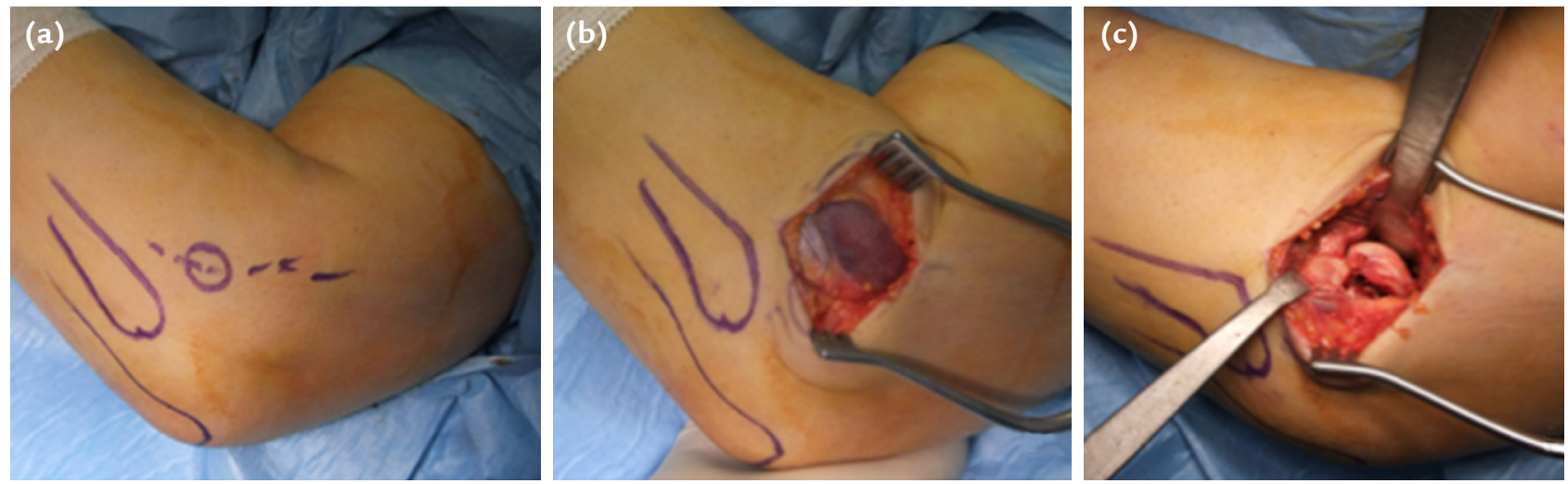

Şekil 3. a-c. Aynı hastanın cerrahi yaklaşımı. Lateral epikondili ortalayacak şekilde yapılan insizyon, radius başının yaklaşık $2 \mathrm{~cm}$ distaline kadar uzatılır (a), ortak ekstansör kasların yapışma yeri anterior kapsül ile birlikte flep şeklinde kaldırılır (b), anterior kapsülün altından mediyal epikondil üzerine bir elevatör yerleştirilerek eklem ve kırık hattı ortaya konmuş olur (c). 


\section{Anterolateral yaklaşım}

Humerus alt uç koronal plan kırıklarının redüksiyon ve tespitinde kırığın tipine bağlı olarak daha çok lateral ve posterior yaklaşımlar tercih ediliyor olsa da anterolateral yaklaşımı öneren yazarlar bulunmaktadır. ${ }^{[19]} \mathrm{Bu}$ yaklaşımda, dirseğin fleksiyon çizgisini S harfi şeklinde geçen bir insizyondan sonra biseps ve brakiyoradyalis kasları arasındaki intervalden girilerek, radyal sinir bulunarak korunur ve sonrasında brakiyalisin hemen altındaki anterior kapsüle ulaşılarak kapsülotomi ile ekleme girilerek redüksiyon ve tespit yapılır.

\section{Artroskopi yardımlı redüksiyon ve tespit}

Özellikle kapitellumun tek ve büyük bir parça olarak kırıldığı Tip 1 kırıklarda kapalı ameliyatların avantajlarından yararlanmak ve komplikasyon riskini azaltmak amacıyla, artroskopi yardımlı redüksiyon ve perkütan kırık tespiti yapılabilmektedir. ${ }^{[20,21]}$ Üç adet portalin kullanıldığı bu yöntem ile Tip 2 kırıklarda da osteokondral fragman eksizyonu ve debridman uygulanabilmektedir. ${ }^{[22]}$

Kırık hattı ortaya konulduktan sonra kapitellum ve trokleadaki parçalanma ve çökme incelenerek, çöken kısımlar kaldırılmalı ve arada kalan metafizyel kemik hasarları greftlenmelidir. Eklem yüzeyinin anatomisi sağlanıp, Kirshner telleri ile geçici tespit yapılarak, skopi ile ya da direkt görerek redüksiyonun yeterli olduğu kontrol edildikten sonra bu K-telleri üzerinden başsız tam yivli kompresyon vidaları, ${ }^{[15]}$ Herbert vida$\operatorname{lar}^{[23,24]}$ ya da kanselöz kanüle vidalar ${ }^{[25,26]}$ yerleştirilerek tespit sağlanır (Şekil 4). Kapitellumun tespitinde

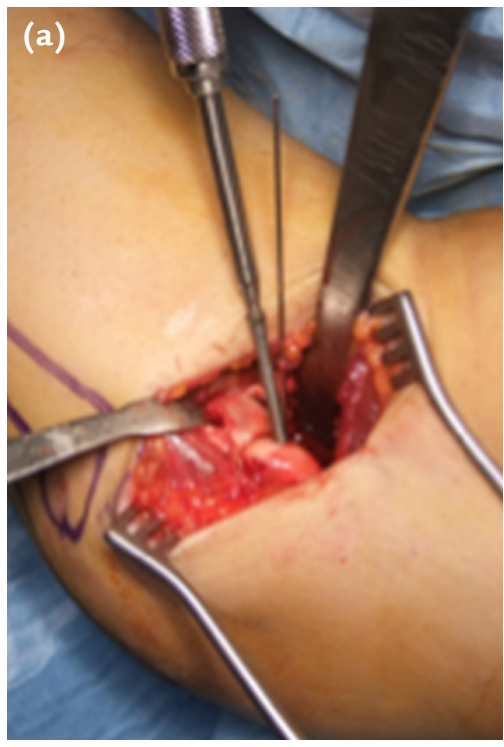

(c)

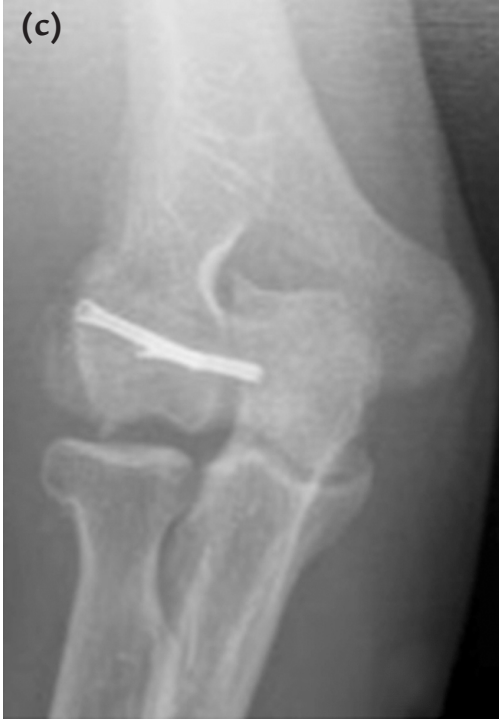

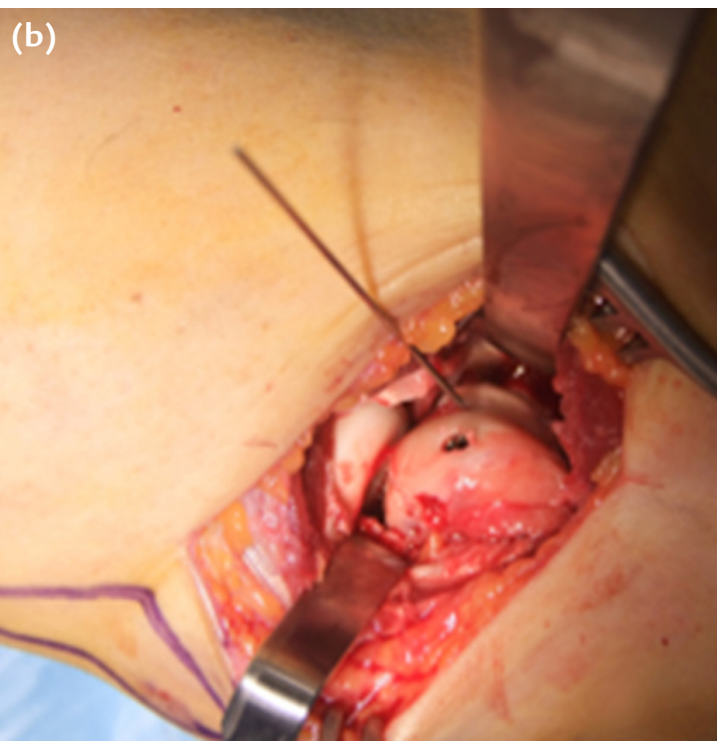

(d)

Şekil 4. a-d. Aynı hastada, kırığın redüksiyonundan sonra K-telleri ile geçici tespit yapılarak redüksiyon kontrol edildi (a), iki adet başsız kanüllü tam yivli kompresyon vidası ile bu K-telleri üzerinden önden arkaya doğru tespit yapıldı (b). Hastanın ameliyat sonrası birinci yılında ön-arka (c) ve yan (d) grafileri görülmektedir. 
başsız tam yivli kompresyon vidalarının Herbert vidası ve spongiyöz lag vidalarına göre biyomekanik olarak daha üstün olduğu gösterilmiştir. ${ }^{[27]}$ Vidalar eklem yüzeyinden anteroposterior yönde veya posteroanterior yönde gönderilebilir. Posteroanterior şeklinde yerleştirilen lag vidalarının, anteroposterior yerleştirilenlere göre daha stabil bir tespit sağladığı bildirilmiştir. ${ }^{[25]}$ Anteroposterior eklem yüzeyinde gönderilen vidaların başsız olmasına ve eklem yüzeyinde çıkıntı olmamasına özen gösterilmesi gerekmektedir, aksi halde artroz riski gündeme gelmektedir. Tip 1 kırıklarda iki adet vida ile tespit yeterli olmaktadır ve bu vidaların kapitellumda iyatrojenik kırıklara neden olmaması için birbirinden yeterli uzaklıkta yerleştirilmeleri önerilmektedir. Tip 3 ve 4 gibi daha kompleks kırıkların tespiti için ise kırık uzanımının ve parçalanmaların olduğu bölgelere ek vidalar, K-telleri veya absorbe olabilen implantlar yerleştirmek gerekebilir. Lateral kolonda parçalanmanın fazla olduğu olgularda ise plak vida ile lateralden destek sağlayarak stabil bir osteosentez elde etmek gerekir. LUKB yaralanmasının eşlik ettiği olgularda, eğer avulsiyon ya da kopma kırığı şeklinde ise, vida ile tespit yapılmalı, fragman vidalanamayacak kadar küçük ise sütür ankor ya da transosseöz sütürler kullanılarak primer tamir yapılmalıdır.

\section{AMELIYAT SONRASI DÖNEM VE TAKIP}

Dirsek, ameliyat sonrası yumuşak doku iyileşmesi sağlanana kadar 7-15 gün süreyle uzun kol atelde tutulur. Sonrasında, eklem içi kırıkların tedavisindeki anatomik redüksiyon, stabil osteosentez ve erken eklem hareketi prensiplerinden yola çıkarak aktif ve aktifyardımlı eklem hareketlerine başlanmalıdır. Dirsek eklem hareket genişliği (ROM) egzersizleri LUKB yaralanması eşlik eden olgularda ön kol pronasyonda iken, mediyal kollateral bağ yaralanması olan olgularda ise ön kol supinasyonda iken yapılmalıdır. Kırık tespitinin yeterince stabil olmadığı olgularda ise ROM egzersizleri geciktirilebilir ve dirsekten menteşeli ortez kullandırılarak yaptırılabilir. Erken dönemde fleksiyon kontraktürü olan olgularda dirseği ekstansiyona zorlayan dinamik ortezler kullanılabilir.

\section{KOMPLIKASYONLAR}

Dirsekte ağrı, sertlik, instabilite, redüksiyon veya tespit kaybı erken dönemde karşılaşılabilecek sorunlardan başlıcalarıdır. Dirsekte fleksiyon kontraktürü ve heterotopik ossifikasyon bu hastalarda ameliyat sonrası dönemde sık karşılaşılan komplikasyonlardandır. Cerrahi müdahalenin yanında bir de kırığın kompleks olması, bağ yaralanmasının eşlik etmesi, ameliyat sırasında brakiyalis kasının bütünlüğünün bozulması, hemartroz ve ameliyat sonrası rehabilitasyona uyum gibi etmenler dirsekte gelişebilecek fleksiyon kontraktürünün derecesini belirler. ${ }^{[28]}$ Fonksiyonel bir dirsek eklemi elde edilemez ise fleksiyon ya da ekstansiyon kontraktürlerini gidermek için serbestleştirme ameliyatları yapılabilir. ${ }^{[3,5]}$ Nadir görülen komplikasyonlardan biri de yumuşak doku bütünlüğünün bozulması veya posterior metafizyel parçalanmaya bağlı olarak gelişebilen kapitellum veya trokleanın avasküler nekrozudur. ${ }^{[1,3]}$ instabilite, osteoartroz, osteonekroz, kaynamama, yanlış kaynama gibi komplikasyonlar sonrasında ciddi şikayetleri olan hastalarda kurtarıcı bir yöntem olarak total dirsek artroplastisi akılda bulundurulmalıdır.

Nadir bir yaralanma olan humerus alt uç koronal plan kırıkları ile ilgili, ülkemizde çok yakın zamanda yayımlanan iki çalışma ile literatüre katkıda bulunulmuştur. Bezmialem Vakıf Üniversitesi ve İstanbul Üniversitesi İstanbul Tıp Fakültesi Ortopedi ve Travmatoloji klinikleri tarafindan yapılan klinik çalışmada, ${ }^{[15]}$ humerus alt uç koronal plan kırığı nedeni ile 2001-2011 yılları arasında, açık yerleştirme ve içsel tespit yöntemi ile tedavi edilmiş, yaş ortalaması 45,3 yıl (16-70) ve ortalama takip süresi 43,6 ay (12-120) olan 18 hasta geriye dönük olarak değerlendirilmiştir. Bryan ve Morrey sınıflamasına göre yedisi Tip 1, beşi Tip 3 ve altısı Tip 4 olarak sınıflandırılan hastalardan 16'sı lateral yaklaşım ve ikisi posterior yaklaşım ile birlikte olekranon osteotomisi uygulanarak tedavi edilmiştir.

Bu tedavilerde, tespit materyali olarak iki hastada Herbert vidası, 13'ünde başsız tam yivli kompresyon vidası ve üçünde kısmi yivli kanselöz kanüle vidalar kullanıldı. Kanüle vidalar arkadan öne doğru, başsız kompresyon vidaları ise uygulama kolaylığı ve kıkırdağa zarar vermemesi nedeniyle önden arkaya doğru yerleştirildi (Şekil 4). Çok parçalı kırıklarda ya da ihtiyaç olduğu durumlarda K-telleri ile de tespit yapıldı. Ameliyat sonrası ortalama 7-15 gün süreyle uzun kol atel uygulanan hastalarda, sonrasında dirsek ROM egzersizlerine başlandı. Tüm hastalar radyografik incelemeler yanında fonksiyonel durum için Mayo dirsek performans indeksi (MEPI) ve el, kol, omuz sakatlık skoru (DASH) ile değerlendirildi. Son kontrollerde sagittal plan eklem hareket açıklığı $8,9^{\circ}-132,8^{\circ}$, ortalama MEPI skoru 86,7 ve DASH skoru 15,3 olarak bulundu. Sonuç olarak 14 hastada mükemmel ve iyi sonuç elde edildi ve hastalar kırık öncesi aktivite seviyelerine ulaştılar (Şekil 5). Hiçbir hastada takipler sırasında posttravmatik artroz veya avasküler nekroz gelişmedi, ancak tanı ve tedavisi geciken bir hastada heterotopik ossifikasyon nedeniyle ikincil cerrahiler gerekti. Fonksiyonel sonuçların hastanın yaşı, cinsiyeti veya kırığın tipi ile ilişkisi olmadığı görüldü. Sonuç 


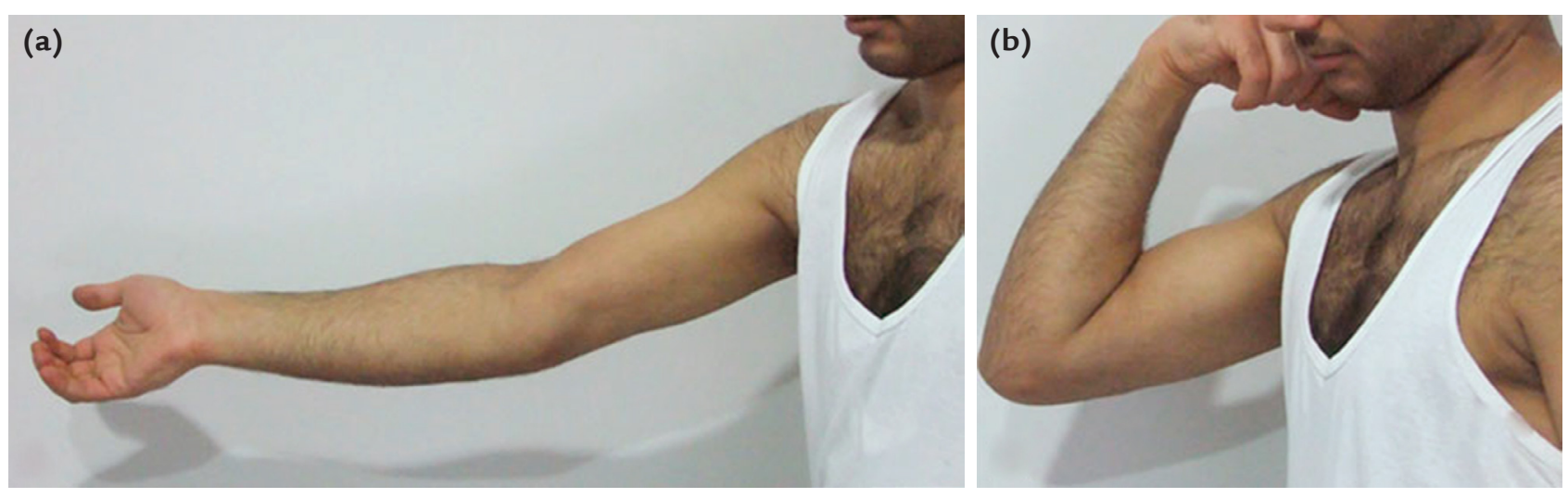

Şekil 5. a, b. Şekil 1'deki hastanın ameliyat sonrası birinci yılında fonksiyonel sonuçları: ekstansiyon (a) ve fleksiyon (b).

olarak erişkinde, humerus distal koronal plan kırıklarında uygulanacak stabil osteosentez ve sonrasında erken hareketin, fonksiyonel sonuçları iyi yönde etkilediği saptandı.

Yine ülkemizde yapılmış olan, Durakbaşa ve arkadaşlarının güncel diğer bir çalışmasında ${ }^{[29]}$ ise ortalama yaşı 36 yıl (11-76), ortalama takip süresi 50 ay (24-91) olan 15 hastanın tümü açık yerleştirme ve içsel tespit yöntemi ile tedavi edilmiş, ortalama MEPI skoru 83,3 bulunmuş, yedi hastada mükemmel, ikisinde iyi ve altısında kötü sonuç elde edildiği bildirilmiştir. Bu seride, dört hastada (\%27) avasküler nekroz, altı hastada (\%40) dejeneratif artrit, altı hastada (\%40) eklem yüzeyinde basamaklaşma, yedi hastada (\%47) heterotopik kemikleşme gelişimi, bir hastada (\%7) kaynamama ve bir hastada da implant yetersizliği görülmüştür. Eklem yüzeyindeki basamaklaşma ve avasküler nekrozun dejeneratif artrit gelişimi ile, yaralanmaya lateral epikondil kırığının eşlik etmesinin ise heterotopik kemikleşme gelişimiyle ileri derecede ilişkili olduğu bildirilmiştir.

Humerus alt ucu lateral kolonunun koronal plandaki kırıkları, izole kırıklar olabileceği gibi bağ yaralanmalarının eşlik edebildiği kompleks dirsek yaralanmalarının bir parçası olarak da ortaya çıkabilirler. Kırığın şekli, uzanımı ve yaralanmanın karmaşıklığı, cerrahi planlama ve implant seçiminde belirleyici rol oynamaktadır. Basit tipteki kırıklarda tam yivli başsız kompresyon vidaları veya kanüllü spongiyöz vidalar ile stabil osteosentez elde edilebilir iken, daha kompleks kırıklarda absorbe edilebilir pinler, mini vidalar yada destek plakvidaları gerekli olabilir.

Erişkin kapitellum ve humerus alt uç koronal plan kırıklarının tedavisinde, erken dirsek hareketine izin veren açı redüksiyon ve internal tespit yöntemi ile iyi fonksiyonel sonuçlar alınabilmektedir. Kırığın tipi ve hastanın yaşına bakmaksızın tedavideki temel hedef, stabil ve anatomik bir redüksiyon elde ederek erken harekete başlamaktır. Bu nedenle, uygun bir şekilde tedavi edilmeyen ya da doğru yöntemler uygulansa bile fizik tedaviye uyumsuzluğu olan hastalarda kötü sonuçlar kaçınılmaz olabilir.

\section{KAYNAKLAR}

1. Ruchelsman DE, Tejwani NC, Kwon YW, Egol KA. Open reduction and internal fixation of capitellar fractures with headless screws. J Bone Joint Surg Am 2008;90(6):1321-9. CrossRef

2. O'Driscoll SW, Morrey BF, Korinek S, An KN. Elbow subluxation and dislocation. A spectrum of instability. Clin Orthop Relat Res 1992;(280):186-97.

3. Dubberley JH, Faber KJ, Macdermid JC, Patterson SD, King GJ. Outcome after open reduction and internal fixation of capitellar and trochlear fractures. J Bone Joint Surg Am 2006;88(1):46-54.

4. McKee MD, Jupiter JB, Bamberger HB. Coronal shear fractures of the distal end of the humerus. J Bone Joint Surg Am 1996;78(1):49-54.

5. Ring D, Jupiter JB, Gulotta L. Articular fractures of the distal part of the humerus. J Bone Joint Surg Am 2003;85-A(2):232-8.

6. Morrey BF, Tanaka S, An KN. Valgus stability of the elbow. A definition of primary and secondary constraints. Clin Orthop Relat Res 1991(265):187-95.

7. Dushuttle RP, Coyle MP, Zawadsky JP, Bloom H. Fractures of the capitellum. J Trauma 1985;25(4):317-21.

8. Doornberg J, Lindenhovius A, Kloen P, van Dijk CN, Zurakowski D, Ring D. Two and three-dimensional computed tomography for the classification and management of distal humeral fractures. Evaluation of reliability and diagnostic accuracy. J Bone Joint Surg Am 2006;88(8):1795-801.

9. Goodman HJ, Choueka J. Complex coronal shear fractures of the distal humerus. Bull Hosp Jt Dis 2005;62(3-4):85-9.

10. Mighell MA, Harkins D, Klein D, Schneider S, Frankle M. Technique for internal fixation of capitellum and lateral trochlea fractures. J Orthop Trauma 2006;20(10):699-704.

11. Bryan RS, Morrey BF. Fractures of the distal humerus. In: Morrey BF, editor. The elbow and its disorders. Philadelphia, PA: WB Saunders; 1985. p.302-39. 
12. Guitton TG, Doornberg JN, Raaymakers EL, Ring D, Kloen P. Fractures of the capitellum and trochlea. J Bone Joint Surg Am 2009;91(2):390-7. CrossRef

13. Ochner RS, Bloom H, Palumbo RC, Coyle MP. Closed reduction of coronal fractures of the capitellum. J Trauma 1996;40(2):199-203.

14. Fowles JV, Kassab MT. Displaced supracondylar fractures of the elbow in children. A report on the fixation of extension and flexion fractures by two lateral percutaneous pins. J Bone Joint Surg Br 1974;56B(3):490-500.

15. Bilsel K, Atalar AC, Erdil M, Elmadag M, Sen C, Demirhan M. Coronal plane fractures of the distal humerus involving the capitellum and trochlea treated with open reduction internal fixation. Arch Orthop Trauma Surg 2013;133(6):797-804. CrossRef

16. Grantham SA, Norris TR, Bush DC. Isolated fracture of the humeral capitellum. Clin Orthop Relat Res 1981(161):262-9.

17. Mancini GB, Fiacca C, Picuti G. Resection of the radial capitellum. Long-term results. Ital J Orthop Traumatol 1989;15(3):295-302.

18. Ring D. Open reduction and internal fixation of an apparent capitellar fracture using an extended lateral exposure. J Hand Surg Am 2009;34(4):739-44. CrossRef

19. Imatani J, Morito $\mathrm{Y}$, Hashizume $\mathrm{H}$, Inoue $\mathrm{H}$. Internal fixation for coronal shear fracture of the distal end of the humerus by the anterolateral approach. J Shoulder Elbow Surg 2001;10(6):554-6.

20. Kuriyama K, Kawanishi Y, Yamamoto K. Arthroscopicassisted reduction and percutaneous fixation for coronal shear fractures of the distal humerus: report of two cases. J Hand Surg Am 2010;35(9):1506-9. CrossRef
21. Hardy P, Menguy F, Guillot S. Arthroscopic treatment of capitellum fracture of the humerus. Arthroscopy 2002;18(4):422-6.

22. Feldman MD. Arthroscopic excision of type II capitellar fractures. Arthroscopy 1997;13(6):743-8.

23. Mahirogullari M, Kiral A, Solakoglu C, Pehlivan O, Akmaz I, Rodop O. Treatment of fractures of the humeral capitellum using herbert screws. J Hand Surg Br 2006;31(3):320-5.

24. Sano S, Rokkaku T, Saito S, Tokunaga S, Abe Y, Moriya H. Herbert screw fixation of capitellar fractures. J Shoulder Elbow Surg 2005;14(3):307-11.

25. Ong KL, Mahadev A. Cannulated cancellous screw fixation for capitellum fractures in adolescents. J Orthop Surg (Hong Kong). 2011;19(3):346-9.

26. Kaya A, Altay T, Karapinar L, Oztürk H, Sürenkök F. Treatment of type I capitellar fractures in adolescents. Ulus Travma Acil Cerrahi Derg 2009;15(3):267-70.

27. Elkowitz SJ, Polatsch DB, Egol KA, Kummer FJ, Koval KJ. Capitellum fractures: a biomechanical evaluation of three fixation methods. J Orthop Trauma 2002;16(7):503-6.

28. Ruchelsman DE, Tejwani NC, Kwon YW, Egol KA. Coronal plane partial articular fractures of the distal humerus: current concepts in management. J Am Acad Orthop Surg 2008;16(12):716-28.

29. Durakbasa MO, Gumussuyu G, Gungor M, Ermis MN. Distal humeral coronal plane fractures: management, complications and outcome. J Shoulder Elbow Surg 2013;22(4):560-6. CrossRef 